\title{
Susuk charms? A case report
}

\author{
M. O. Sharif, ${ }^{* 1}$ K. Horner, ${ }_{1}^{2}$ S. Chadwick ${ }^{3}$ and C. West ${ }^{4}$
}
IN BRIEF
- Introduces susuk charms.
- Provides background information on susuk charms.
- Demonstrates a comprehensive use of current knowledge and non-invasive techniques to tentatively diagnose the objects.

\section{INTRODUCTION}

This case report describes the incidental finding of what are believed to be susuk charms identified by radiographic investigations taken before orthodontic treatment. The orthopantomogram (OPG) and lateral cephalogram are the two most common radiographs used by orthodontists. These views provide invaluable information relating to the developing dentition, crown-root ratios, skeletal and dental relationships. In accordance with national requirements for radiological practice, ${ }^{1}$ it is imperative that clinicians requesting or taking these views perform a complete evaluation (report) of their radiographic investigations.

The majority of incidental, non-dental, findings in dental radiography are dominated by maxillary sinus inflammatory disease, or root filling materials/instruments found within the peri-apical region. ${ }^{2}$ However, there have also been reports of gunshot pellets, objects pushed up into the nasal cavity by children, ${ }^{2}$ haemangiomas ${ }^{3}$ and fibro-osseous lesions. ${ }^{4}$

In this paper we describe a case in which bilateral radio-opaque objects in the mandibular rami region were

${ }^{1 *} \mathrm{NIHR}$ Academic Clinical Fellow - Orthodontics, ${ }^{2}$ Professor of Oral and Maxillofacial Imaging, ${ }^{3}$ Consultant and Specialist in Orthodontics, ${ }^{4}$ Clinical Teaching Fellow and Specialist in Orthodontics, School of Dentistry, University of Manchester, Manchester, M13 9PL *Correspondence to: Mohammad Owaise Sharif Email:mohammad.sharif@manchester.ac.uk

\section{Refereed Paper}

Accepted 18 March 2013

DOI: 10.1038/sj.bdj.2013.630

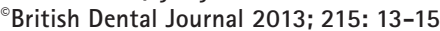

located as an incidental finding on a panoramic radiograph.

\section{CASE REPORT}

AT, a 15-year-old female was referred by her general dental practitioner (GDP) to the orthodontic department at The University Dental Hospital of Manchester. The reason for referral was crowding and advice regarding the management of her carious 15 and 16 teeth. Medically AT was fit and well.

An orthodontic assessment revealed that AT had Class III incisors on a Class III skeletal base, moderate upper arch crowding with upper lateral incisors in cross-bite, a buccally displaced 13 , mild lower arch crowding and the presence of all teeth including developing wisdom teeth. She had an IOTN dental health component score of $4 \mathrm{~d}$ and an aesthetic component score of 8 .

As part of the assessment before orthodontic treatment a panoramic radiograph was taken to inform diagnosis and treatment planning. The panoramic radiograph revealed five small radio-opaque objects bilaterally in the region of the mandibular rami distal to the developing third molars (Fig. 1). AT and her parents were questioned regarding any previous surgery/ intervention in the orofacial region or any episodes of general anaesthesia. None were reported and her medical history was clear. The patient and her parents maintained they had no knowledge as to what the objects on the radiograph might be. On further questioning it emerged that AT had moved to the UK from Mongolia

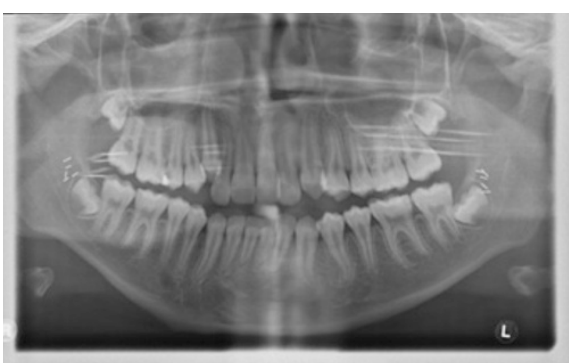

Fig 1. AT's panoramic radiograph showing the presence of all permanent teeth including developing third molars. Note the secondary images of the objects streaked across the contra-lateral side of the radiograph

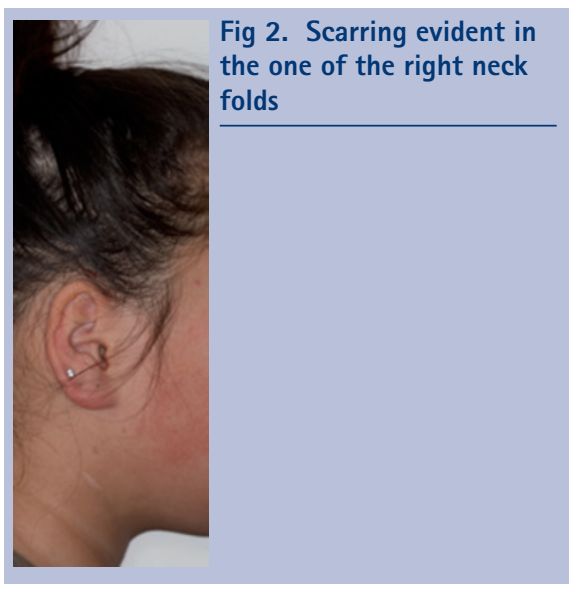

when she was two years old and this suggested the objects may have been placed before AT moved to the UK. A thorough extra-oral examination revealed some scarring in one of AT's right neck folds (Fig. 2); on questioning both AT and her parents reported being unaware of any cause or explanation for this. Intraorally, palpation and visual examination did not reveal the location/presence of the objects. 
As part of a complete orthodontic assessment a lateral cephalogram was taken. Once again the presence of the radio-opaque objects was evident (Fig. 3).

To more accurately locate and to help identify the objects a limited volume cone beam computed tomography (CBCT) was requested and performed in August 2012. This confirmed the presence of multiple radiopacities of metallic density outside bone, medial to the mandibular rami, distal to the third molars. The objects were almost symmetrical and consisted of two well-localised collections of five cylindrical radiopacities, of metallic density, lying within soft tissue 3-4 mm medial to the medial aspect of the mandible just anterior to the tonsil regions. Each individual radiopacity had a similar size (length $=3 \mathrm{~mm}$, width $<1 \mathrm{~mm}$ ) and shape (straight, probably cylindrical). Beam hardening artefacts were found to arise from the radiopacities, consistent with a high atomic number material for example, gold (Fig 4).

An ENT surgeon was contacted with the images to query the presence of surgical clips in the tonsillar region. His opinion was that, although some surgeons did use surgical clips in tonsillectomy procedures, due to the morphology of the radiopaque objects these could be ruled out as a possibility.

The radio-opaque objects were strikingly similar to brachytherapy beads used in the management of cancer. Therefore in September 2012, a medical physicist was called upon to assess the objects for radioactivity using a Geiger counter. The test revealed no emission of radioactivity.

\section{DISCUSSION}

After a thorough search of the literature and contact with international experts, there are no previous reports of similar radio-opaque objects (that is, being placed bilaterally medial to the mandibular rami region) being encountered on radiography.

Radiopaque objects have been used in the past for assessing facial growth, however, the markers are placed in specific locations, in hard tissue not soft tissue and these sites are selected for their stability. ${ }^{5-7}$ The objects in this case are not in these locations and their morphology is not typical of implants conventionally used for these studies.
These images were posted, with an anonymised case history on an international oral radiology discussion group (ORADLIST), ${ }^{8}$ to which numerous specialist oral radiologists throughout the world are subscribed. This process revealed an additional potential diagnosis: susuk charm needles.

The differential diagnosis the authors devised, the investigations performed and conclusions reached are summarised in Table 1.

\section{WHAT IS SUSUK?}

Susuks are charm needles inserted subcutaneously in the orofacial and other bodily regions. ${ }^{9}$ They are approximately 0.5 $\mathrm{mm}$ in diameter and 5-10 $\mathrm{mm}$ in length and composed of solid gold, silver or diamonds. ${ }^{10,11}$ Hence these charm needles can be very biocompatible and remain hidden for many years; sometimes the presence of the charm is hidden from the wearer.

Nambiar et al. reported an increased incidence of susuk in Malay Muslim women and a common site is the maxillofacial region. ${ }^{12}$ One case series on susuk in the orofacial region reported that susuk recipients may be forbidden from eating certain types of food (for example, bananas). ${ }^{9}$

AT and her parents were subsequently questioned about the possibility of susuk; all reported no knowledge of their presence. However, this would be expected in light of the nature of the beliefs surrounding susuk. The susuk talismans are believed to preserve the wearer's youth, beauty and charisma. They are used to offer protection against minor ailments, injury or harm but can also be placed to ensure business success rather than for medical reasons. The hidden talismans are kept secret as failure to do so removes the potency of the charm.

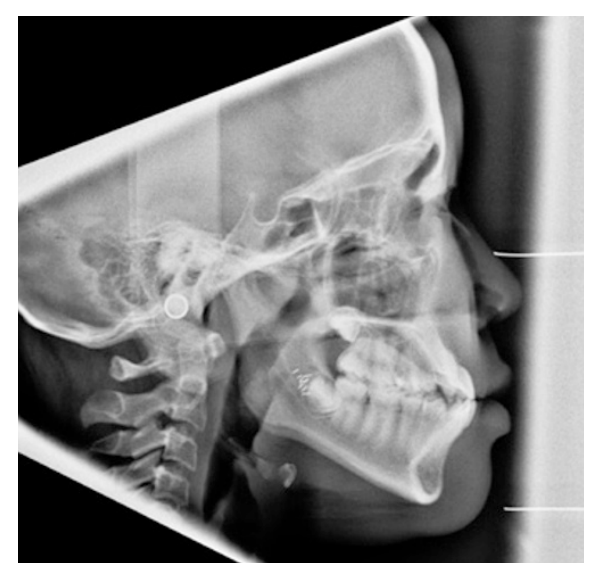

Fig 3. AT's Lateral Cephalogram

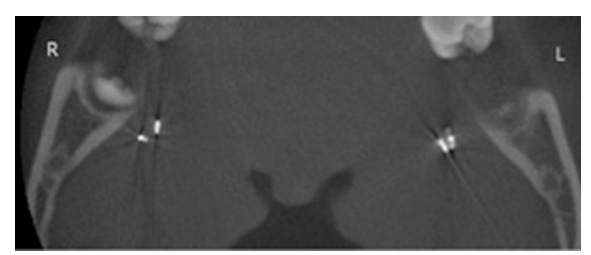

Fig 4. СВCT image - Axial view showing metallic objects medial to the mandibular rami bilaterally

\section{PREVIOUS REPORTS OF SUSUK IN THE OROFACIAL REGION}

A review of the literature revealed several case reports of susuk in the orofacial region..$^{913-15}$ The number of susuk charms per patient in the orofacial region ranged from 1-80. Although susuk may be inserted symmetrically, ${ }^{16}$ none of the published case reports demonstrated the presence of susuk bilaterally medial to the mandibular rami. Furthermore, all insertions appeared to be subcutaneous rather than intra-oral.

\section{WHAT COULD THE OBJECTS IN THIS CASE BE?}

After excluding all other possibilities it is most likely that the objects are susuk charms.

Table 1 A summary of the differential diagnosis the authors devised, the investigations performed and conclusions reached

\begin{tabular}{|c|c|c|}
\hline Potential origin of object & Investigation/action to confirm/refute & Conclusion \\
\hline Surgical clips & $\begin{array}{l}\mathrm{DPR}, \mathrm{CBCT} \text { and opinion of an ENT } \\
\text { surgeon. No apparent history of surgery }\end{array}$ & $\begin{array}{l}\text { Unlikely. Conventional clips are } \\
\text { of a differing morphology }\end{array}$ \\
\hline Brachytherapy beads & $\begin{array}{l}\text { Geiger counter and opinion of an expert } \\
\text { in nuclear medicine }\end{array}$ & $\begin{array}{l}\text { Unlikely, but excluded by lack } \\
\text { of radioactivity }\end{array}$ \\
\hline $\begin{array}{l}\text { Markers for a } \\
\text { growth study }\end{array}$ & $\begin{array}{l}\text { Questioning parents about knowledge of } \\
\text { inclusion in such a study. } \\
\text { Opinion of a consultant orthodontist }\end{array}$ & Unlikely \\
\hline Earrings/jewellery & $\begin{array}{l}\text { Visual examination prior to imaging. } \\
\text { Opinion of a consultant radiologist }\end{array}$ & $\begin{array}{l}\text { Nothing of this nature present } \\
\text { when imaging }\end{array}$ \\
\hline Cultural & $\begin{array}{l}\text { Questioning patient and parents. } \\
\text { Opinion of radiologists internationally }\end{array}$ & $\begin{array}{l}\text { Potentially susuk charms, } \\
\text { although not seen in this } \\
\text { region previously }\end{array}$ \\
\hline
\end{tabular}




\section{THE USE OF CBCT IN THIS CASE}

CBCT was used as a means of accurately localising the radiopaque objects. Because this technique requires a higher X-ray exposure than conventional radiographic techniques, justification and optimisation are essential, particularly in a young person. In this case, while conventional facial bone views might have sufficed in providing approximate localisation of the foreign bodies, CBCT provided exact information, and an undistorted assessment of object dimensions. In terms of optimisation of exposure, a 'low dose protocol' was used (half rotation), along with reduction of tube current. Consequently, the effective dose would probably have been about $40-50 \%$ of the reported $54 \mu \mathrm{Sv}$ for this scanner and field of view. ${ }^{17}$

\section{CONCLUSION}

This case describes a previously unreported finding, the origin of which cannot be definitively identified using current knowledge and literature, but which has been tentatively identified as susuk by a process of exclusion of other possibilities. To date the radiopaque objects remain in situ without a definitive diagnosis and AT is undergoing a course of treatment within the orthodontic department at The University Dental Hospital of Manchester. In the long term there is a need for ongoing clinical review; it is possible that the foreign bodies may appear at the surface and be exfoliated at some point.

The authors would like to thank Susi Caldwell (consultant orthodontist, Manchester) for kindly providing comments on the initial draft of this manuscript.

1. National Radiological Protection Board. 2001 guidance notes for dental practitioners on the safe use of $X$-ray equipment. London: Department of Health, 2001.

2. Wenham K, Craig S, Tsitrou E. The incidental finding of a retained gunshot pellet. Dent Update 2009; 36: 28-30.

3. Gadhia K, Bunyan R, Chan C-H. Multiple radioopacities in an OPG: a case report of cavernous haemangioma of temporalis muscle with multiple phleboliths. Dent Update 2011; 38: 711-713.

4. Piattelli A, Perfetti G, Carraro A. Complex odontoma as a periapical and interradicular radiopacity in a primary molar. J Endod 1996: 22: 561-563.

5. Björk A. Facial growth in man, studied with the aid of metallic implants. Acta Odontol Scand 1955; 13: $9-34$
6. Björk A. Variations in the growth pattern of the human mandible: longitudinal radiographic study by the implant method. J Dent Res 1963. 42: 400-411.

7. Björk $A$. The use of metallic implants in the study of facial growth in children: method and application. Am J Phys Anthropol 1968; 29: 243-254.

8. Oradlist - Oral Radiology Discussion Group. Secondary Oradlist - Oral Radiology Discussion Group. http://lists.ucla.edu/cgi-bin/mailman/ listinfo/oradlist.

9. Shanmuhasuntharam P, Ghani S H. Susuks: charm needles in facial soft tissues. Br Dent J 1991; 170: 309-311.

10. Echols J M, Shadily H U. An Indonesian-English Dictionary. New York: Cornell University Press, 1989

11. Loh F C, Ling S Y. Analysis of the metallic composition of orofacial talismans. Oral Surg Oral Med Oral Pathol 1992; 73: 281-283.

12. Nambiar P, Ibrahim N, Tandjung $Y$ R. M, Shanmuhasuntharam P. Susuks (charm needles) in the craniofacial region. Oral Radiol 2008. 24: $10-15$.

13. Loh F C, Yeo J F. Talisman in the orofacial region. Oral Surg Oral Med Oral Pathol 1989; 68: 252-255.

14. Nor M M, Yushar A, Razali M, Rahman R A, Ramli $R$. Incidental radiological findings of susuk in the orofacial region. Dentomaxillofac Radiol 2006; 35: $473-474$.

15. Teo S K. A woman with hidden charm needles. J R Coll Physicians Edinb 2006; 36: 211-212.

16. Soo Y S, Singh J. Some radiological observation on the practice of insertion of charm needles. Med J Malaya 1972; 27: 40-42.

17. Pauwels $R$, Beinsberger J, Collaert $B$ et al. Effective dose range for dental cone beam computed tomography scanners. Eur J Radio/ 2012; 81: 267-271. 